\title{
SISTEMAS DE GOBIERNO
}

\author{
SÁNCHEZ VELÁZQUEZ, Katia Cristina ${ }^{125}$ \\ SuMARIO: 1. Introducción. - 2. Sistemas de Gobierno. - 3. Democracia. - 4. \\ Clasificación de los Sistemas de Gobierno. - 5. Conclusiones.
}

\section{Introducción}

Desde la antigüedad, los seres humanos nos hemos organizado en sociedades más o menos complejas, en torno a centros de poder que muy probablemente tuvieron su origen en las figuras de autoridad familiar, ya sea materna o paterna, de manera que en muchas culturas el rey era considerado como el padre del pueblo; desde entonces conforme los grupos sociales fueron aumentando en tamaño y complejidad, esta figura de autoridad comenzó a ser ejercida por grupos sociales definidos, como los nobles, cuyo parentesco con el monarca les significaba una posición de privilegio dentro de la comunidad. ${ }^{126}$

Antes del nacimiento de la democracia, la mayoría de los estados estaban gobernados por las aristocracias, que como sabemos era el gobierno de un reducido grupo de personas que por lo general eran provenientes de familias nobles.

Los sistemas de gobiernos existentes en los diferentes países pueden ser clasificados según el régimen político de cada uno de ellos. En el presente trabajo daremos a conocer los diversos tipos de gobierno existentes, entre los cuales existen regímenes políticos en el que todos los poderes se hallan concentrados bajo una autoridad única sin limitaciones para gobernar, denominados regímenes dictatoriales hasta regímenes democráticos en el cual el pueblo es el que ejerce la soberanía por si mismo a

${ }^{125}$ Alumna de la Facultad de Derecho y Ciencias Políticas, estudiante del Instituto Cultural Peruano Norteamericano

${ }^{126}$ http://amoxcalli.leon.uia.mx/Epikeia/numeros/09/epikeia09-

los_sistemas_de_gobierno.pdf 
través del sufragio y en el que existe además la separación de poderes: Ejecutivo, legislativo y judicial.

\section{Sistemas de Gobierno}

Es la forma de gobierno en la que se hace referencia al modelo de organización del poder constitucional que adopta un Estado en función de la relación existente entre los distintos poderes; es decir, la manera en la que se estructura el poder político para ejercer su autoridad en el Estado. Bidart Campos ${ }^{127}$ sostiene que un sistema de gobierno es la manera de organizar y distribuir las estructuras y competencias de los órganos que componen el gobierno.

\section{Democracia}

El vocablo democracia deriva del griego DEMOS: pueblo y KRATOS: gobierno o autoridad. Esto quiere decir que significa gobierno del pueblo. ${ }^{128}$

La democracia es una forma de gobierno, de organización de Estado, en la cual las decisiones colectivas son adoptadas por el pueblo mediante mecanismos de participación directa e indirecta que les confieren legitimidad a los representantes. Se dice que existe democracia directa cuando la decisión es adoptada directamente por los miembros del pueblo; y existe democracia indirecta cuando la decisión es adoptada por personas reconocidas por el pueblo como sus representantes. ${ }^{129}$

Pero la democracia no solo es una forma de gobierno, sino también un estilo de vida basado en el respeto de la libertad y la dignidad de la persona humana.

Robert A. Dahl, en su libro Poliarquía propone ocho criterios para definir y medir la democracia, estos son:

a) El derecho de voto

b) El derecho a ser elegido

c) El derecho de los lideres políticos a competir para conseguir apoyo y votos

d) Elecciones libres y justas

${ }^{127}$ Bidart CAmpos. Derecho político. Buenos Aires, 1972.

128 http://www.elprisma.com/apuntes/ciencias_politicas/democracia/

129 http://solo-historia.blogspot.com/2008/10/20-aos-del-plebiscito.html 
e) Libertad de asociación

f) Libertad de expresión

g) Fuentes alternativas de información

h) Instituciones para hacer que las políticas públicas dependan de los votos y otras expresiones de preferencia. ${ }^{130}$

Además se puede definir a la democracia como el método y la técnica que permite a los ciudadanos elegir a los dirigentes, quienes se encuentran controlados y responsabilizados en los marcos que señala el orden jurídico del país, con la finalidad de garantizar el goce de los derechos humanos. ${ }^{131}$

Por ello, para lograr una democracia se requiere la participación ciudadana; esta es un conjunto de mecanismos a través de los cuales los ciudadanos buscan incidir en las decisiones públicas con el fin de que estas representen sus intereses sociales. ${ }^{132}$ Algunas de las formas de participación se dan a través del:

- Voto.

- Plebiscito

- Referéndum

- Iniciativa Popular, a través de este el pueblo puede proponer la sanción o derogación de una ley.

\section{Clasificación de Los Sistemas de Gobierno}

\section{1) La República}

Proviene del latín RES, por lo que significa cosa pública.

Es la forma de gobierno de los países en los que el pueblo tiene la soberanía o facultad para el ejercicio del poder, aunque sea delegado por el pueblo soberano en gobernantes que elige de un modo u otro.

Una característica fundamental del sistema republicano es la separación de poderes, constitucionalmente establecida, los cuales son tres: El Poder Ejecutivo, el Poder Legislativo y el Poder Judicial.

Otra característica fundamental son la igualdad ante de la ley de todos los ciudadanos; los gobernantes son responsables ante el pueblo que los eligió, por sus actos

${ }^{130}$ LIJPHART AREND, Modelos de democracia: Formas de Gobierno y resultados en treinta y seis países. Barcelona, pág. 59.

${ }^{131}$ CARPIZO, JORGE. Concepto de democracia y Sistema de Gobierno en América Latina, II ed., pp. 109-120.

132 http://www.ciudadanosaldia.org/repositorio/ppts/ppt_viva_informado_230607.pdf 
de gobierno; y la publicidad de dichos actos, que no deben ser secretos, sino puestos a conocimiento del público para poder ser controlados.

Dentro de la República existen sistemas Presidenciales y Parlamentarios, a continuación analizaremos las diferencias de ambas.

a) Características del sistema parlamentario:

-Los miembros del gabinete (Poder Ejecutivo) son también miembros del parlamento (Poder Legislativo).

-El gabinete está integrado por los dirigentes del partido mayoritario o por los jefes de los partidos que por coalición forman la mayoría parlamentaria.

- El Poder Ejecutivo es doble: existe un jefe de Estado que tiene principalmente funciones de representación y protocolo, y un jefe de Gobierno; este ultimo conduce la administración y al Gobierno mismo.

-En el gabinete existe una persona que tiene supremacía y a quien se suele denominar primer ministro.

-El gabinete subsistirá, siempre y cuando cuente con el apoyo de la mayoría parlamentaria.

b) Características del sistema presidencial: Tuvo su origen en los Estados Unidos de América

- $\quad$ El Poder Ejecutivo es Unitario. Está depositado en un presidente que es, al mismo tiempo, jefe de Estado y jefe de Gobierno.

- $\quad$ El presidente es electo por el pueblo y no por el Poder Legislativo, lo cual le da independencia frente a éste.

- $\quad$ El presidente generalmente nombra y remueve libremente a los secretarios de Estado.

- $\quad$ Ni el presidente ni los secretarios de Estado son políticamente responsables ante el congreso.

- $\quad \mathrm{Ni}$ el presidente ni los secretarios de Estado, como regla general, pueden ser miembros del congreso.

- $\quad$ El presidente puede estar afiliado a un partido político diferente al de la mayoría del congreso.

- $\quad$ El presidente no puede disolver el congreso. ${ }^{133}$

\section{2) La Monarquía}

La monarquía es la forma de gobierno en el que el poder es ejercido por una sola persona, que se llama el monarca, rey o príncipe; se da por elección o generalmente a título vitalicio y designado según un orden hereditario.

${ }^{133}$ CARPIZO JORGE, Concepto de democracia y Sistema de Gobierno en América Latina, II ed., pp. 43-55. 
Formas de Monarquia:

a) Monarquía Absoluta: Es aquella en que no existe limitación alguna a la autoridad del monarca.

b) Monarquía Constitucional: Aquella en que los poderes del monarca están delimitados por una ley o una Constitución.

\section{3) Dictadura}

Es una forma de gobierno autoritario, según el cual una persona, o un grupo de personas asume el poder político de modo absoluto e irrestricto, con el objeto de responder a una necesidad excepcional de fortalecimiento del Estado. Además de asumir sin limitación y de modo absoluto las funciones integras de la soberanía, lo cual causa la ausencia de poderes.

Esta forma política, también se caracteriza por no permitir la intervención de la voluntad de los ciudadanos. ${ }^{134}$

\section{Conclusiones}

En estos tiempos modernos en que la mayoría de los países vivimos en democracia, el sistema de gobierno que debe prevalecer a mi concepto es el sistema de gobierno republicano, el mismo que se fundamenta en el principio de la elección de los gobernantes por el pueblo, mediante representantes libremente elegidos por sufragio universal y mediante el principio de la división de poderes.

\footnotetext{
${ }^{134}$ http://www.me.gov.ar/efeme/24demarzo/quees3.html
} 


\section{SISTEMAS DE GOBIERNO}

\section{BIBLIOGRAFÍA}

LIJPHART AREND, Modelos de democracia: Formas de Gobierno y resultados en treinta y seis países. Barcelona, pág. 59; CARPIZO, JORGE. Concepto de democracia y Sistema de Gobierno en América Latina, II ed., pp. 109-120; BIDART CAMPOS. Derecho político. Buenos Aires, 1972; ROCIO DEL PIAR VERASTEGUI LEDESMA., El sistema de Gobierno en los sistemas políticos democráticos: Presidencialismo y parlamentarismo. Del libro Sistemas y Regímenes Políticos Comparados, pág. 97-99; C.R. AGUILERA DE PRAT RAFAEL MARTÍNEZ “Sistemas de Gobierno, partidos y territorio. Pág. 81-95; CARPIZO JORGE, Concepto de democracia y Sistema de Gobierno en América Latina, II ed., pp. 43-55; ROCIO DEL PIAR VERASTEGUI LEDESMA. El sistema de Gobierno en los sistemas políticos democráticos: Presidencialismo y parlamentarismo. Del libro Sistemas y Regímenes Políticos Comparados, pág. 116

http://www.me.gov.ar/efeme/24demarzo/quees3.html

http://amoxcalli.leon.uia.mx/Epikeia/numeros/09/epikeia09-

los_sistemas_de_gobierno.pdf

http://www.elprisma.com/apuntes/ciencias_politicas/democracia/

http://solo-historia.blogspot.com/2008/10/20-aos-del-plebiscito.html

http://www.ciudadanosaldia.org/repositorio/ppts/ppt_viva_informado_230607.pdf 